\title{
CHANGES IN SOCIAL ORGANIZATION DURING THE BREEDING SEASON OF WILD TALAPOIN MONKEYS
}

\author{
T. E. ROWELL AND A. F. DIXSON* \\ Department of Zoology, University of California, Berkeley, California, and \\ *Oregon Regional Primate Research Center, Beaverton, Oregon, U.S.A.
}

(Received 24th September 1974)

\begin{abstract}
Summary. Two adjacent troops of talapoin monkeys were studied near Mbalmayo, Cameroon, during a predicted 3-month breeding season. Mating continued for just over 2 months. One troop began to mate at least 2 weeks before the other, suggesting that, though climatic changes were probably important, precise timing was mediated through some intra-troop social facilitation effect.

Before the breeding season, adult males and females lived in separate sub-groups. Males began to move into female sub-groups before there was any sign of the perineal swellings characteristic of receptive talapoin females. Copulation occurred only with females with medium or large swellings, except towards the end of the season. It is probable that the majority of females were monoestrous. At the height of the mating period, females joined mainly male sub-groups, leaving their infants with the mainly female groups which also included a few males. Copulations were observed in both these types of sub-groups. Consort behaviour was not observed, males frequently returning to all-male sub-groups immediately after ejaculation. Intersexual grooming was not characteristic of sexual interactions. At the end of the season, adults were seen more frequently in groups of their own sex or with juveniles only, and there was some indication that increased aggressiveness by newly pregnant females might be partly responsible for this separation.
\end{abstract}

\section{INTRODUGTION}

Talapoin monkeys in the Mbalmayo Forest Reserve, Cameroon, were found to live in a troop of over seventy animals, within which sub-groups of three main types were identified. These were composed of adult and large juvenile males (called 'all-male sub-groups'), adult females with infants, small juveniles, and large juvenile females (called 'female-infant sub-groups'), or medium-sized juveniles with a single adult male (called 'juvenile sub-groups'). These subgroupings did not cover all associations seen, but variations were rare, so that, for example, no overt interactions between adult males and adult females were recorded (Rowell, 1973).

Those observations were made during October to December 1971, a period 
when all adult females were carrying young infants. Gautier-Hion (1968) had established that talapoins have an annual brief breeding season, lasting just over 2 months. A study of J. H. Wolfheim (unpublished) 6 months after the first study at the Mbalmayo site established that a birth season occurred in June to August, implying a mating season in January to March, or starting immediately after the end of the first study. We therefore returned a third time in January to March 1974 to see how the unusual social organization reported earlier would change to accommodate mating.

Scruton \& Herbert (1970), in their study of menstrual cycles and sexual behaviour of captive talapoins, did not recognize seasonality in breeding but concentrated on changes within the menstrual cycle. They reported that copulation was largely confined to females with large swellings. Seasonality has been found by T. E. Rowell (unpublished), in whose breeding colony females show an acyclic period from about March to September.

Courtship in the talapoin has been described as particularly elaborate by Gautier-Hion (1971b) and by Wolfheim \& Rowell (1972), who attributed its length and variety to fear on the part of the male of the higher-ranking female, who might, if not maximally receptive, turn and attack him, supported by other females in the group. Gautier-Hion also stressed consortship in the mating behaviour of talapoins, i.e. close and continued interaction of male and female between copulations, but neither of the present authors saw evidence of such behaviour in captivity. In small captive groups, a hierarchy was formed in which females ranked above all males and only the highest ranking male copulated (Dixson, Everitt, Herbert, Rugman \& Scruton, 1973). It seemed unlikely, however, that in a large wild troop only one male would do all the mating. We expected the present study to provide more data on some discrepancies between laboratory and field observations, and to clarify the status of some of the features of social behaviour which have been attributed to this unusual species.

\section{MATERIALS AND METHODS}

\section{Study site and methods of observation}

An account of the natural history of talapoins in the Mbalmayo forest reserve has been given elsewhere (Rowell, 1972) and agrees in the main with that of Gautier-Hion (1966, 1971a) for talapoins in N.E. Gabon. Observations took place between 5 January and 26 March 1974. Each observer worked throughout with one of two adjacent troops, the one which had been the object of the two previous studies, $\mathrm{T}$ troop, and its downstream neighbour, A troop. It was easier to remain in contact with $T$ troop because its routes were already known and it was to some extent habituated to being followed. Table 1 shows the sizes of the two troops and the time spent in contact with each.

Observations were made with $10 \times 40$ binoculars except when the light was insufficient, when $7 \times 41$ power were used. Truly systematic observations of small monkeys in dense foliage are impossible, but the same routine was used as in the previous study: besides recording all overt social interaction, any monkey which came in sight was classified as to age, sex, and reproductive 
condition, and then its nearest visible neighbour was identified similarly. This process was continued for as long as the sub-group remained in sight. Attention was then turned to a sub-group in a different quadrant of the field of view, and the first sub-group was not recounted as long as it remained identifiable as such, to avoid as far as possible making repeat counts. Animals recorded in the same sub-group are described as 'in association'.

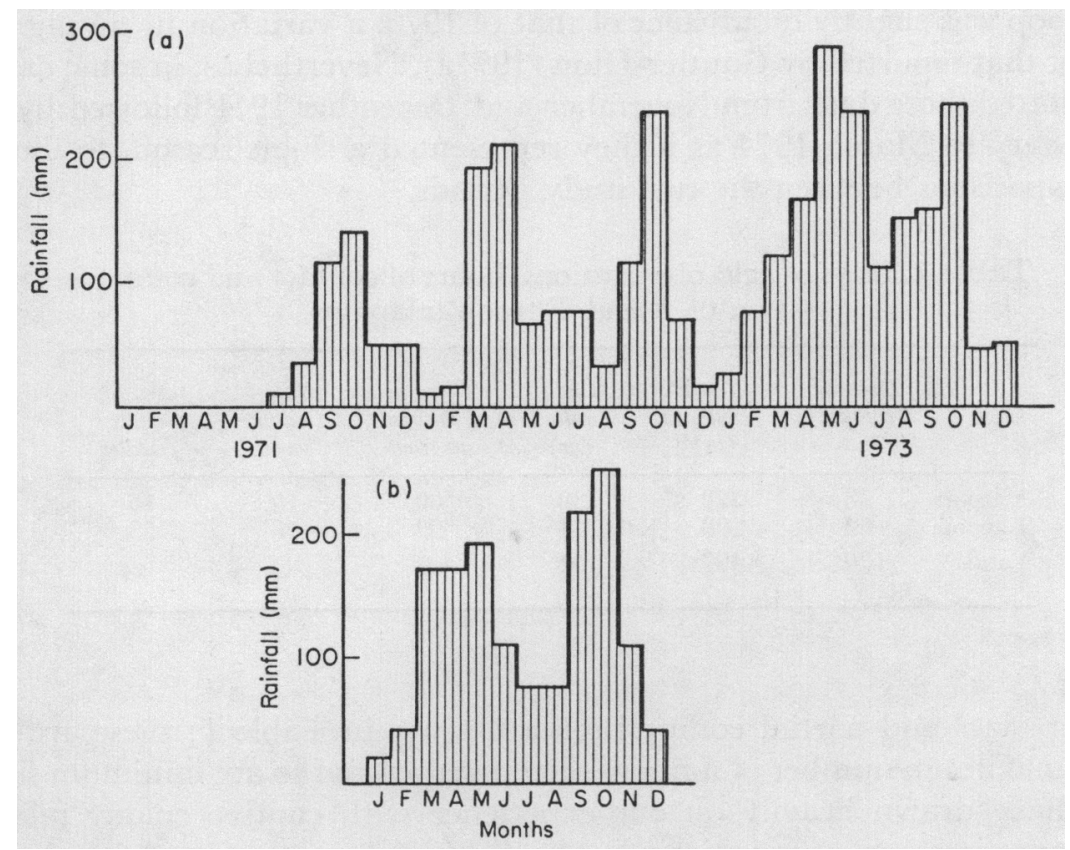

Text-FIG. 1. Monthly rainfall in the Nyong and Soo Department of South-Gentral Cameroon. Figures were obtained from the Department of Agriculture. (a) The average rainfall/month over the period of the studies; (b) a summary of the average rainfall over 3 years.

\section{Seasonality}

Seasons are identified in equatorial regions by rainfall. At Mbalmayo, annual temperature changes are insignificant, daylength is almost constant, but there are two wet and two dry seasons each year (Text-fig. 1): December to February is the long dry season (when there may be periods of 7 to 10 days without rain). The heavy rains start in March and continue through May. A relatively dry period occurs from June through August, and there is a second shorter wet season in September and October, breaking some time in November. The timing of these seasons may vary by 2 or 3 weeks. At Mbalmayo, talapoins mate in the long dry season and give birth in the short dry season. In N.E. Gabon, at Gautier-Hion's study site, about $300 \mathrm{~km}$ away to the south east, the long dry season is in June to August, the short dry season being in December and January, almost exactly the reverse of the seasons at Mbalmayo. The breeding seasons of the talapoins are also reversed there, copulations occurring in June through August and births in December and January. 
These associated reversals very strongly suggest that the mating season is triggered by stimuli produced by the dry season itself rather than by sidereal clues.

It can be seen from Text-fig. 1(a) that the dry season started abruptly in early November in both 1971 and 1973 (though 1973 was the wetter year). In the 1971 study, the first incipient perineal swelling of the season was seen on the last day of the study (22 December), so it is probable that the breeding season of $\mathrm{T}$ troop was slightly in advance of that of 1973, a variation in timing of the order of that reported by Gautier-Hion (1971a). Nevertheless, in some cases we have plotted those data from November and December 1971 followed by those for January to March 1974 as if they represented a single season, to illustrate the comparisons between the two study periods.

Table 1. Days of field observations, hours of contact and composition of $\mathrm{A}$ and $\mathrm{T}$ troop talapoins

\begin{tabular}{lcccccc}
\hline & $\begin{array}{c}\text { Days of } \\
\text { contact }\end{array}$ & $\begin{array}{c}\text { Total } \\
\text { contact } \\
(\text { hr })\end{array}$ & $\begin{array}{c}\text { Good } \\
\text { contact } \\
(\text { hr })\end{array}$ & $\begin{array}{c}\text { Total no. } \\
\text { of animals } \\
\text { in troop }\end{array}$ & $\begin{array}{c}\text { No. of } \\
\text { adult } \\
\text { males }\end{array}$ & $\begin{array}{c}\text { No. of } \\
\text { adult } \\
\text { females }\end{array}$ \\
\hline A troop & 58 & 229 & 30 & 80 & 10 & 16 \\
T troop & 62 & 268 & 74 & 92 & 16 & 25 \\
Total & 120 & 497 & 104 & & & \\
\hline
\end{tabular}

\section{Animals}

Troop sizes and partial composition are given in Table 1; these are based on the maximum number of animals seen together and so are minimum figures.

We have drawn heavily on our experience with captive colony talapoins in interpreting our observations in the field. Where the captivity data are not yet published, the initials of the author responsible are inserted in parentheses after the statement.

Identification of animals had to be rigorous to support the interpretations presented. Thus, adults were only identified if a clear view of genitalia, or nipples of adult females, was obtained. Juveniles were identified by size: in a good view large, medium, and small could be distinguished, corresponding to the 3 years before adolescence, but for the purposes of this paper the only distinction made is between 'small' juveniles, aged 6 to 9 months and still sometimes carried by their mothers, and 'large' juveniles of older groups.

Animals in their 4th year were entering their first breeding season. There was no sharp distinction between older and younger adult males and these adolescents, and any male with clearly descended testes was classed as 'adult'. Some of these would certainly have still been classed as large juvenile males 2 months earlier, as puberty seems to occur just before a breeding season. Similarly, there was a recognizable class of nulliparous females entering their first mating season. They had small nipples, and their perineal swellings were characteristic, with large clitoral lobes but little dorsolateral involvement of the perineum, the perineal skin partly retaining the slate colour of the juvenile perineum, not pale pink like that of older adult females. These females were 
classed as 'adult females'. Towards the end of the mating period, some mediumsized juvenile females developed small vulval swellings which attracted the interest of their male peers and occasional adult males. Interpretation of the developmental history of swellings is based on observations of a captive breeding colony (T.R.; T. H. Glewe, personal communication).

Adult female talapoins undergoing menstrual cycles in captivity show perineal swellings which increase gradually to a maximum during the follicular phase of the cycle and decrease rapidly during the first part of the luteal phase (Scruton \& Herbert, 1970). Both observers were familiar with the appearance of swellings at different stages of the cycle, and, with good visibility, were able to classify the swellings according to criteria used in our laboratories; detumescing swellings could be recognized by the change from a shiny to a wrinkled appearance, and towards the end of the study some females had a perineum which recognizably indicated early pregnancy. Visibility was not always perfect, however, so for purposes of calculation the state of the perineum was described as 'small or zero' or 'medium to large' in size, the latter roughly corresponding to the swellings of females in the receptive phase (follicular) of the cycle.

Communicative behaviour of talapoins has been described elsewhere (Gautier-Hion, 1971b; Wolfheim \& Rowell, 1972; Dixson, Scruton \& Herbert, 1975). The sequences of social interaction observed were necessarily fragmentary because of the dense vegetation, but since both observers were practised in recording social interactions in captive groups, short sequences were readily identifiable. More could be heard than seen of the animals' activities, and some noises could be used unequivocally to identify interaction patterns, e.g. copulation is often accompanied by a highly characteristic noise made by both male and female. We also identified 'excitement choruses' (including the 'pant-chirp' of Wolf heim \& Rowell, 1972) and 'fight squeals' (including the 'screech' of Wolf heim \& Rowell, 1972). These were groups of rather variable noises rather than single vocalizations, but the two groups were reasonably easy to distinguish.

\section{RESULTS}

\section{Time course of the mating season}

The study period was divided into six periods of about 2 weeks each, with approximately equal time in contact with the talapoins in each. As can be seen from Table 2, data collection became more efficient as the study progressed and both monkeys and observers became more habituated; data were always sufficient, however, for comparisons between 2-week periods to be made. Text-figure 2 shows the \% of all females identified which had medium to large swellings in each period. In T troop, there were no females with swellings in this category during the first 2 weeks of the study, and there were still two females with large swellings remaining at the end. In A troop, females with swellings were observed at the first sighting of the troop, but only one female continued swollen into the last 2-week period. Comparison of the two troops suggests that they had breeding seasons of very similar time course, but 2 weeks out of phase, which is rather a large difference in such a short season. (Another troop which lived on the opposite bank of the Nyong was regularly seen and seemed from the 
Table 2. Identifications of adult females and associations recorded for talapoins in Troops $\mathrm{A}$ and $\mathrm{T}$ between January and March

\begin{tabular}{|c|c|c|c|c|c|c|}
\hline & \multicolumn{2}{|c|}{ January } & \multicolumn{2}{|c|}{ February } & \multicolumn{2}{|c|}{ March } \\
\hline & Early & Late & Early & Late & Early & Late \\
\hline $\begin{array}{l}\text { Hours of contact } \\
\text { Troop A } \\
\text { Troop T }\end{array}$ & $\begin{array}{l}44 \\
51\end{array}$ & $\begin{array}{l}42 \\
43\end{array}$ & $\begin{array}{l}38 \\
42\end{array}$ & $\begin{array}{l}39 \\
45\end{array}$ & $\begin{array}{l}31 \\
47\end{array}$ & $\begin{array}{l}35 \\
37\end{array}$ \\
\hline $\begin{array}{l}\text { Identifications of adult females } \\
\text { Troop A } \\
\text { Troop T }\end{array}$ & $\begin{array}{l}28 \\
27\end{array}$ & $\begin{array}{l}77 \\
92\end{array}$ & $\begin{array}{r}84 \\
110\end{array}$ & $\begin{array}{r}70 \\
172\end{array}$ & $\begin{array}{r}70 \\
239\end{array}$ & $\begin{array}{r}90 \\
211\end{array}$ \\
\hline $\begin{array}{l}\text { All associations recorded } \\
\text { Troop A } \\
\text { Troop T }\end{array}$ & $\begin{array}{l}40 \\
69\end{array}$ & $\begin{array}{l}80 \\
87\end{array}$ & $\begin{array}{r}85 \\
122\end{array}$ & $\begin{array}{l}84 \\
92\end{array}$ & $\begin{array}{r}77 \\
169\end{array}$ & $\begin{array}{r}81 \\
153\end{array}$ \\
\hline $\begin{array}{l}\text { Associations including adult mal } \\
\text { Troop A } \\
\text { Troop T }\end{array}$ & $\begin{array}{r}\text { les } \\
13 \\
37\end{array}$ & $\begin{array}{l}42 \\
54\end{array}$ & $\begin{array}{l}51 \\
75\end{array}$ & $\begin{array}{l}59 \\
70\end{array}$ & $\begin{array}{r}37 \\
102\end{array}$ & $\begin{array}{l}32 \\
95\end{array}$ \\
\hline
\end{tabular}

pattern of vocalization to be rather behind $\mathrm{T}$ troop, while the troop downstream of A troop was probably ahead, as it seemed to be in mid-season at the start of the study.) It is difficult to imagine an environmental difference in these adjacent home ranges which could have caused such a difference in timing.

The frequency of copulations recorded followed a similar curve to the sightings of medium-to-large swellings (Text-fig. 3). When copulations were observed, they were usually of females with large swellings. Towards the end of the season, however, when few females with swellings remained, an adult male was seen to copulate, with difficulty, with a juvenile female with a small vulval swelling; another copulated with an adult female with no swelling at all, and at this

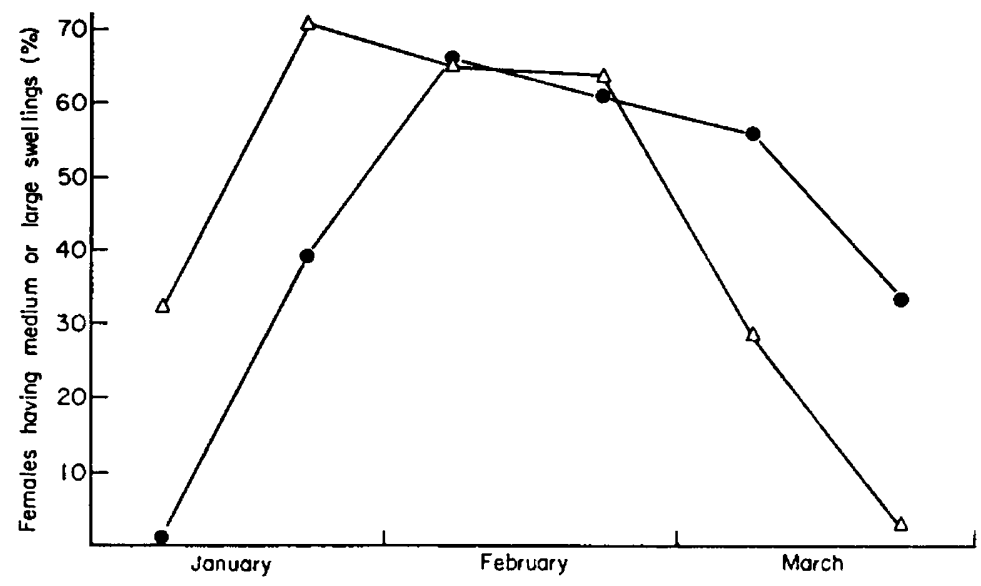

TEXT-FIG. 2. Observations of females showing medium or large perineal swellings in two adjacent talapoin troops, $\mathrm{A}(\Delta)$ and $\mathrm{T}(\bullet)$. The total number of observations of females with identified swelling size were 419 for $A$ troop, and 851 for $T$ troop. The proportion of females with larger swellings was generally overestimated because they were easier to identify. 


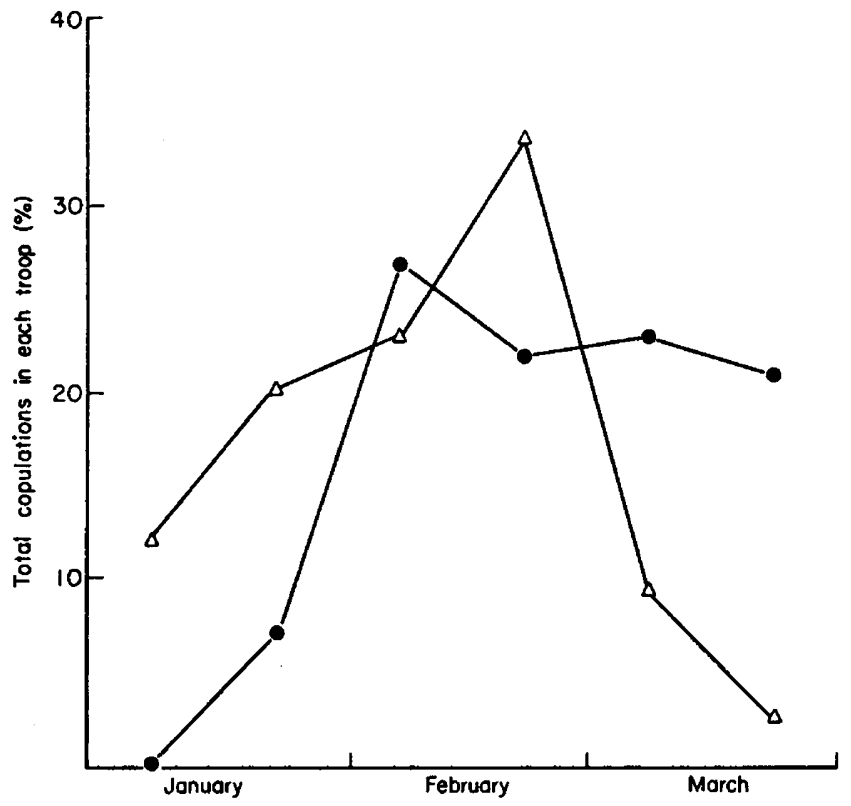

TexT-FIG. 3. Distribution of the total copulations recorded in the 2-week sections of the study period for $A(\Delta)$ and $T(\theta)$ troop talapoins. The total number of observations for $T$ troop was 118 and for $A$ troop was 40.

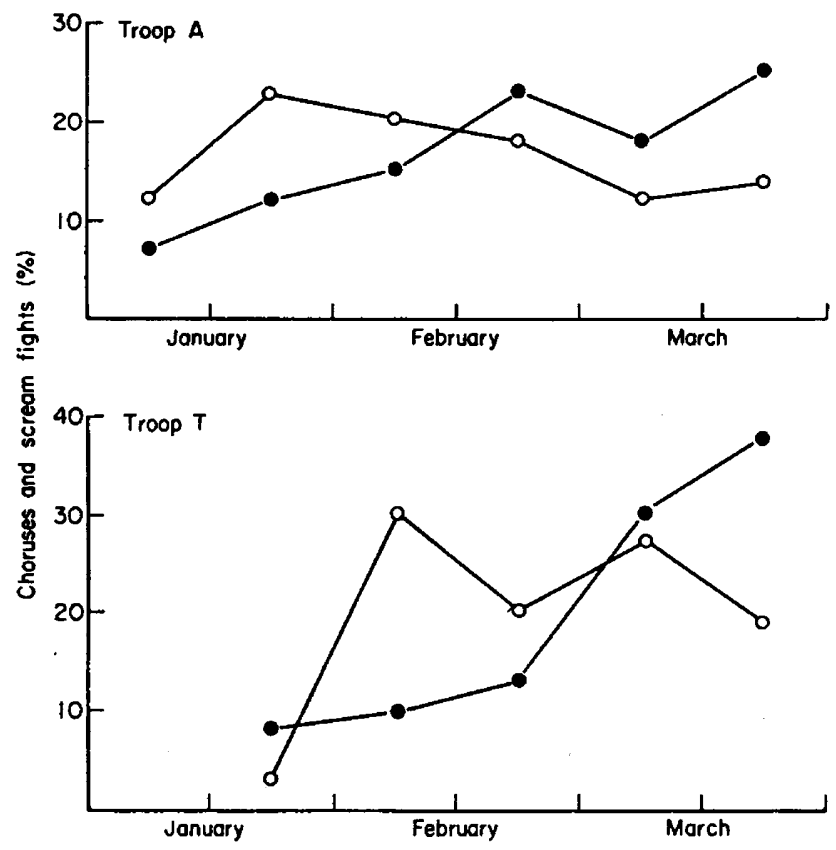

Texr-pig. 4. Distribution of total excitement choruses (O) and scream fights (e) heard in $A$ and $T$ troop talapoins over the study period. The total number of choruses was: A troop, 325; $\mathrm{T}$ troop, 545. The total number of scream fights was: A troop, 359; $\mathrm{T}$ troop, 272. 
time also copulations were seen with females that looked to be detumescing, rather than in the late follicular phase, to which receptivity is typically confined. Nulliparous captive females have been seen to copulate in early pregnancy, especially when other females present are in the late follicular phase of the cycle (T.R.).

\section{The start of the mating season}

The first change in group behaviour began in December of the first study of $T$ troop: groups of adult and large juvenile males began to mob and chase each other very conspicuously through the higher branches. Supporting males mounted and embraced each other, but when such an interaction could be followed for any length of time individuals could be seen to change sides frequently. This behaviour was accompanied by excitement choruses, which could be identified and scored very much more frequently than the behaviour could be followed. Choruses continued into the breeding season, but became less frequent towards the end (Text-fig. 4).

The next change was that occasional adult males were sighted in association with adult female/infant sub-groups during progressions. In the first study, a few such associations were seen in late December; before that males and females were seen together only when passing incidentally through the same tree, or during alarm reactions. Similar associations were seen from the beginning of the present study in $\mathbf{T}$ group, before any female had shown signs of perineal swelling. No sexual behaviour was seen or heard in this group for a further 10 days, by which time some females had developed medium to large swellings. In the pre-mating and post-mating phases, males and females were in association with their own sex or with juveniles, whereas during the mating season, when most females had a swollen perineum, more than $50 \%$ of sightings of either sex were in heterosexual associations, so that an attractive function for the swellings is not ruled out. Nulliparous females were prominent among the first cohort of females to begin to mate, and the last females to swell were multiparous adults.

\section{The end of the mating season}

Mating was last seen only a week before the end of the study in A troop and there were still two females with large swellings in T troop. Some changes in behaviour, however, indicated how the season might be brought to an end.

During the last 2 or 3 weeks, copulations were seen with seemingly less than optimally attractive females (judging by perineal condition). Both males and females were increasingly observed in sub-groups of their own sex or with juveniles. In both A and T troops 'fight squeals' were heard more frequently as the mating season went on (Text-fig. 4). Most fights were heard rather than seen, so it is not known whether this increase in fighting was associated with an increase in female aggression towards males. Of the few interactions in $T$ troop where at least the aggressor was identified, more than half the aggression by females was seen in March. Male aggression was equally frequent throughout the study, and males were aggressors about twice as often as females over-all; both sexes were about twice as aggressive in the breeding season as in the period preceding it. Both males and females mainly attacked adult and large juvenile males (Table 3). 
Table 3. Incidence of aggression by adult male and female talapoins in $\mathrm{T}$ troop

\begin{tabular}{lrrrrrrr}
\hline & \multicolumn{2}{c}{1971} & & \multicolumn{3}{c}{1974} \\
\cline { 2 - 3 } \cline { 6 - 7 } & Nov. & Dec. & Jan. & Feb. & March \\
\hline No. of aggressive males & 9 & 6 & 17 & 12 & 16 \\
No. of aggressive females & 2 & 1 & 6 & 2 & 14 \\
\hline
\end{tabular}

Grooming among all classes was seen less frequently at the height of the mating season, and increased greatly as mating became less frequent (Text-fig. 5). The most frequent combinations were adult females grooming juveniles, juveniles grooming each other, and juveniles grooming adult males, combinations which were also frequent in the October-to-December study of $T$ troop. Adult males were seen grooming adult males less frequently than before. In the mating season, adult or large juvenile females were seen to groom adult males six times out of a total of eighty records for $\mathrm{T}$ troop, and once out of thirty records for A troop. Grooming is not a prominent part of sexual interaction in this species.

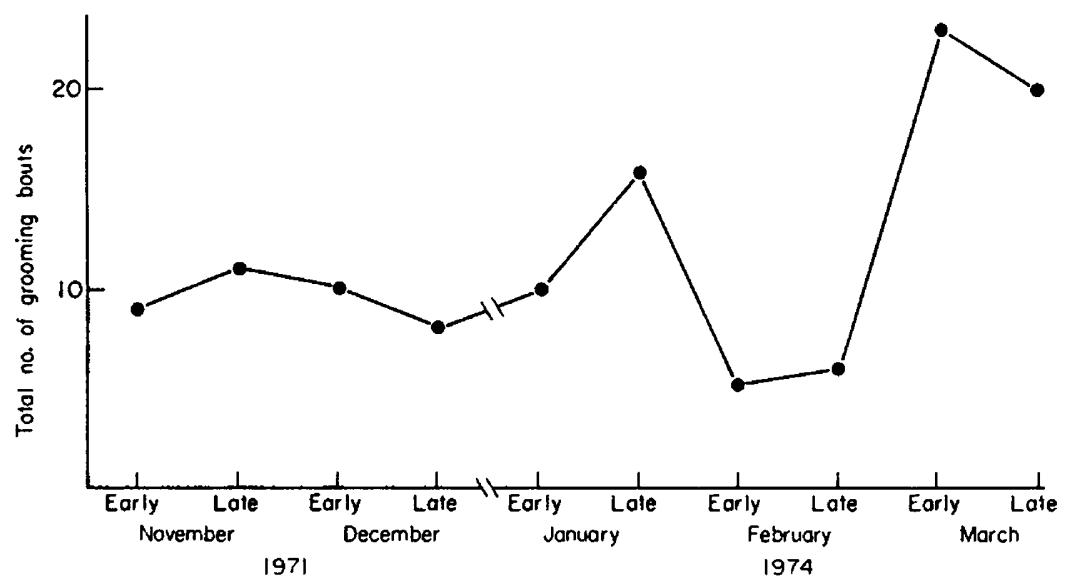

Text-Fig. 5. Frequency of grooming by all classes of talapoins in $T$ troop during the two study periods.

\section{Mating behaviour}

Twenty-four copulations were observed: ten in A troop, fourteen in T troop. The perineum of three of the females was not seen; a female with no swelling and a medium-sized juvenile mated, both in the last fortnight of the study; all other copulations were with females with large- or medium-sized swellings, and often the pinkness or the shininess of the swelling was commented on in the notes. There were only four instances of aggressive response (hit or threat) to male courtship in this study. As far as could be observed, completed copulations seemed to be preceded by less courtship in the wild than in captivity; a male approach elicited presentation, and the male mounted after one or two visual inspections of the perineum only. 
We were unable to find evidence for continuing consort pairs in either troop. Although 125 associations of a single male and a female (with or without a small juvenile) were recorded, most of these were very short, the pair being formed or broken while under observation even though such a pair was never in sight for more than a few minutes. In a typical copulation, a male would approach a female from 20 or 30 yards and, after mating, each would leave in a different direction. Sometimes, it was possible to follow and see the female forming a new association with other females, and the male rejoining an all-male sub-group. A male leaving a heterosexual group after copulation and rejoining an all-male group was an especially frequent occurrence when courtship was seen and the actual copulation only heard as well as after observed copulations. Grooming, as stated above, was rarely seen in precopulatory pairs and never following copulation.

It was clear that most or all adult males were actively breeding, even though we were unable to distinguish many individuals reliably. Copulations were occurring in several sub-groups at once at the height of the breeding season, and copulations within one sub-group were often heard only a few minutes apart. The minimum recorded inter-ejaculatory interval for captive males is $35 \mathrm{~min}$ (T.R.) and $45 \mathrm{~min}$ to $1 \mathrm{hr}$ is usual. A fully receptive female, however, will return to courtship 5 or $10 \mathrm{~min}$ after copulation (T.R.). It seems certain, therefore, that females were being mated by successive males, with males that had recently ejaculated probably leaving the heterosexual group as described above. We had the impression that copulations usually occurred at a distance from other males, and that males were tensely aware of other males during courtship and broke off interactions if other males approached. We did see, however, a male observing courtship and copulation of another male with apparent indifference.

The most frequently observed component of courtship is genital inspection, which is easy to recognize because it is accompanied by exaggerated peering postures. Inspection was seen both as a prelude to copulation and by itself as a brief interaction. Males of all ages, adults more often than juveniles, were seen to inspect females with all sizes of perineal swelling, but about $90 \%$ of inspections were of medium or large swellings. Most of the inspections of a small or flat perineum, or of juvenile females with swellings, occurred in March after the peak of the season was passed (Tables 4 and 5).

\section{Social organization during the mating season}

Throughout the second study, the association types which had been most frequent in the first study were seen (Table 6). As soon as the mating season began, however, associations including both males and females became most frequent.

Male/female associations began before any female had a swollen perineum. A higher proportion $(76 \%)$ of the associations of females with a swollen perineum included males than did the associations (48\%) of females with small or no swelling (data for both troops taken together). The preference of males was less easy to determine because the availability of females with large swellings varied throughout the study. Also, females with large swellings and females with 
Table 4. Perineal swelling sizes of females and number of inspections by male talapoins

\begin{tabular}{lccc}
\hline & \multicolumn{3}{c}{ Swelling sizes } \\
\cline { 2 - 4 } & Nil or small & Medium or large & \\
\hline Inspections by adult males & 8 & 26 & 34 \\
Inspections by juvenile males & 3 & 20 & 23 \\
Total & 11 & 46 & \\
\hline
\end{tabular}

Table 5. Inspections by adult and juvenile male talapoins in Troops $\mathrm{A}$ and $\mathrm{T}$ at different times during the study period

\begin{tabular}{|c|c|c|c|c|c|c|}
\hline \multirow{2}{*}{$\begin{array}{c}\text { Genital } \\
\text { inspection } \\
\text { by males }\end{array}$} & \multicolumn{2}{|c|}{ Fanuary } & \multicolumn{2}{|c|}{ February } & \multicolumn{2}{|c|}{ March } \\
\hline & Early & Late & Early & Late & Early & Late \\
\hline $\begin{array}{l}\text { Troop A } \\
\text { Troop T }\end{array}$ & $\begin{array}{l}2 \\
2\end{array}$ & $\begin{array}{l}8 \\
3\end{array}$ & $\begin{array}{l}8 \\
7\end{array}$ & $\begin{array}{l}10 \\
11\end{array}$ & $\begin{array}{l}3 \\
8\end{array}$ & $\begin{array}{r}1 \\
14\end{array}$ \\
\hline Total & 4 & 11 & 15 & 21 & 11 & 15 \\
\hline
\end{tabular}

The data include all inspections by males, even if the size of the perineal swellings was not observed.

Table 6. Association types of talapoins seen in Troop T

\begin{tabular}{|c|c|c|c|c|c|c|}
\hline & $\begin{array}{c}\text { Adult males } \\
+ \text { large } \\
\text { juveniles }\end{array}$ & $\begin{array}{c}\text { Aduit males } \\
\text { +other } \\
\text { juveniles }\end{array}$ & $\begin{array}{c}\text { Adult } \\
\text { females } \\
\text { only, or } \\
\text { with small } \\
\text { juveniles }\end{array}$ & $\begin{array}{c}\text { Adult males } \\
\text { +adult } \\
\text { females } \\
\text { (+ small } \\
\text { juveniles) }\end{array}$ & $\begin{array}{c}\text { Juveniles } \\
\text { only }\end{array}$ & $\begin{array}{c}\text { Total no. } \\
\text { of } \\
\text { associations } \\
\text { observed }\end{array}$ \\
\hline $\begin{array}{l}\text { Early Nov. } \\
\text { Late Nov. } \\
\text { Early Dec. } \\
\text { Late Dec. }\end{array}$ & $\begin{array}{l}29 \\
35 \\
40 \\
34\end{array}$ & $\begin{array}{r}20 \\
13 \\
7 \\
13\end{array}$ & $\begin{array}{l}34 \\
30 \\
36 \\
40\end{array}$ & $\begin{array}{r}0 \\
10 \\
5 \\
4\end{array}$ & $\begin{array}{l}17 \\
13 \\
10 \\
10\end{array}$ & $\begin{array}{r}59 \\
120 \\
68 \\
48\end{array}$ \\
\hline $\begin{array}{l}\text { Early Jan. } \\
\text { Late Jan. } \\
\text { Early Feb. } \\
\text { Late Feb. } \\
\text { Early March } \\
\text { Late March }\end{array}$ & $\begin{array}{l}16 \\
19 \\
18 \\
16 \\
18 \\
16\end{array}$ & $\begin{array}{r}15 \\
5 \\
5 \\
6 \\
3 \\
8\end{array}$ & $\begin{array}{l}31 \\
24 \\
25 \\
15 \\
26 \\
23\end{array}$ & $\begin{array}{l}23 \\
39 \\
41 \\
58 \\
45 \\
38\end{array}$ & $\begin{array}{r}13 \\
12 \\
11 \\
3 \\
6 \\
12\end{array}$ & $\begin{array}{r}61 \\
78 \\
112 \\
87 \\
149 \\
146\end{array}$ \\
\hline
\end{tabular}

The figures are $\%$ of total associations recorded in each 2-week period in November and December 1971 and January, February and March 1974. 
small or no swellings stayed together, so males which might have been primarily associating with the receptive female were recorded also as being with her non-receptive friends. Over-all, there was a positive correlation between the proportion of females sighted with medium to large swellings and the frequency of male/female associations in each 2-week period (Text-fig. 6).

Male/female associations seemed to fall into two distinct types. In the premating period, an occasional male was recorded in what appeared otherwise to be female-and-small-juvenile sub-groups. This type of sub-group was seen throughout the study. At the height of the mating period, there was typically more than one male, but females always outnumbered males by a large margin,

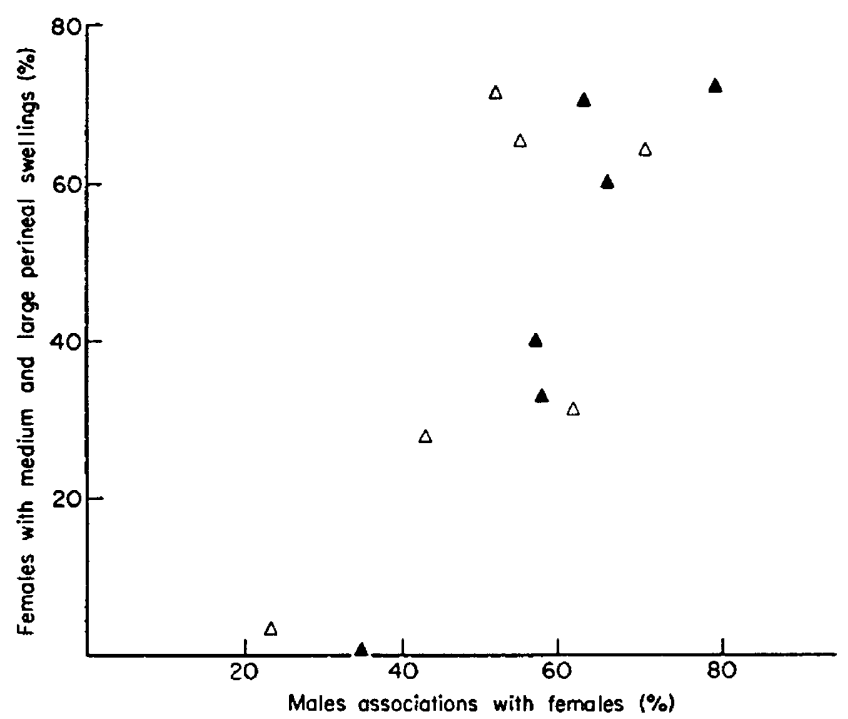

Text-Fig. 6. Relationship between percentage of females which had medium or large swellings and the percentage of male associations which included females in $A(\Delta)$ and $T$ (A) troop talapoins. Each point represents data from one 2-week period.

and small- and medium-sized juveniles outnumbered the adult females. Later in the mating season, a second type of sub-group appeared in which males outnumbered females, and there were no juveniles with the females. As this type became more frequent, the proportion of small juveniles in sub-groups of the first type increased. Receptive females appeared to be leaving their infants with the other small juveniles in the mainly female groups. The mainly male mixedsex groups behaved like all-male groups, travelling high in the trees and jumping conspicuously, while the mainly female sub-groups tended to stay lower, in thicker cover, and move slower, as is typical of all-female groups. If the group were alarmed, females would return, presumably from mainly male groups, and collect their infants. Females with large perineal swellings were more frequent in the mainly male groups, and females with small swellings were more frequently seen associated with small juveniles; but large and small swellings and copulations occurred in both types of sub-group.

This over-all interpretation of the sub-groups seen is difficult to demonstrate 
numerically because it is the result of a synthesis of field observations of differing levels of completeness and reliability. Table 7 shows data which support the interpretation given. Male/female associations are divided according to whether males or females were most numerous in the sub-group, and according to whether small juveniles were present or absent. Heterosexual pairs are a special case and are tabulated separately. Females in pairs usually were not accompanied by their most recent offspring. Table 7 shows that sub-groups in which males outnumbered females were significantly less likely to include small juveniles. Small juveniles were most frequently sighted in male/female sub-groups in which females outnumbered males $(P<0 \cdot 01)$.

Table 7. Frequency of observations, in both troops, of sub-groups containing different proportions of adult male and adult female talapoins, according to whether small juveniles were also observed in the sub-group

\begin{tabular}{lccc}
\hline & $\begin{array}{c}\text { Small juveniles } \\
\text { present }\end{array}$ & $\begin{array}{c}\text { Small juveniles } \\
\text { absent }\end{array}$ & Total \\
\hline $\begin{array}{l}\text { Pairs (1 male+1 female) } \\
\begin{array}{l}\text { No. of males equal to or more } \\
\text { than no. of females in group }\end{array}\end{array}$ & 23 & 55 & 78 \\
$\begin{array}{l}\text { No. of males fewer than no. of } \\
\text { females in group }\end{array}$ & 56 & 77 & 97 \\
\hline
\end{tabular}

\section{DISCUSSION}

The majority of species of primates for which data are available breed seasonally (Vandenbergh, 1973), but seasonality of breeding has been less extensively studied than have other aspects of reproduction in primates. Van Horn (1975) has shown experimentally that decreasing daylength brings ring-tailed lemurs into oestrus. Decreasing daylength is a likely cue in higher latitudes; macaques in the wild, and indeed most monkeys in zoos, tend to conceive in the autumn and give birth in the spring. Daylength cues are improbable, however, within $4^{\circ}$ of the equator, where the changes are between wet and dry season. Talapoins and several other species of forest monkey (Gautier-Hion, 1968) seem to mate only in the long dry season in West Central Africa. The question then is how a wet or dry season is identified. Various species of birds and amphibia have been shown to respond to falling rain, or to changes in vegetation resulting from rain, though these were all species living in arid areas and needing rain in order to breed. Tropical rain forest plants grow and fruit at specific seasons, though the different species are not synchronized. There would be a wealth of vegetational cues available if the wetness itself was not responded to directly by the animals. There are also differences in illumination according to cloud cover in wet and dry seasons which might provide another cue.

One timing factor especially important to the talapoin must be the development of independence in the infants of the previous year. A talapoin infant at 6 months weighs about $450 \mathrm{~g}$, nearly half the mother's weight, and some at 
least were frequently carried well into the mating season. Mothers must use a lot of energy in caring for their infants until they become sufficiently independent to be left for extended periods. In comparison, a baboon infant at the same age weighs only a quarter of the mother's weight and also shows a much higher degree of locomotor independence. The finding that nulliparous females generally began to cycle earlier than most females with young supports this suggestion. By contrast, Kaufman (1965) found that adult female rhesus monkeys mated first, and adolescents later.

The talapoin breeding season was short, with all females coming into heat and conceiving within 2 months. Most, if not all, must have been 'monoestrous'. By comparison, in a small captive troop, although all live births have occurred in June and July, females complete two or three menstrual cycles before conceiving: mating starts in September (possibly in response to decreasing daylength) and continues until February or later (T.R.). A more precise cue than the change from wet to dry season appears to be required to explain such a high degree of synchronization in the wild. Besides being so much shorter, the breeding season in the wild involves much greater social disruption than occurs in captive groups. The mutual chasing, mobbing, and mounting of the adult and large juvenile males before and during the mating period ensured a high level of activity. We speculate that the females might be stimulated by this increase in social activity around them, so that it could function as an agent of synchronization of receptivity, and so of conceptions. Baldwin (1970) suggested a comparable synchronization method in squirrel monkeys, and a similar increase in male agonistic behaviour just before and during the breeding season is reported for rhesus monkeys (Wilson \& Boelkins, 1970). We detected no evidence that the male interaction was competitive in that individuals were excluded from mating. On the contrary, it seemed that females probably mated with several males in rapid succession, and males made no attempt to stay with females after they had copulated; we found no evidence of consort pair formation. At least a large proportion, if not all the adult males must have been mating.

A social rather than an environmental ultimate precipitating factor in starting the breeding season is strongly suggested by the different timing of the adjacent troops in the present study. Once mating had begun, the sight, sound, and smell of breeding activity around them would also be available to stimulate females to receptivity. It is perhaps significant that, as in previous studies at this site, and in those of Gautier-Hion (1966, 1968, 1971a), we again found no evidence of encounters between troops, so that synchronization of social stimuli between troops was apparently not possible.

On the basis of mating behaviour seen in captivity, Rowell (1973) predicted that, when receptive, wild females would leave all-female groups and join the males, returning to the female group after mating. This prediction was only partly realized, and underestimated the disruption produced when a large number of females were simultaneously receptive. The first changes observed were in male behaviour: intra-sexual chasing and mounting and movement of a few males into the female sub-groups. Since these first intersexual associations preceded development of perineal swellings, it is obvious that the swellings could 
not be the primary attractant. On the other hand, once the season started, the more females there were in the group with large swellings, the more males were found associated with females. This observation would be consistent with the hypothesis that males were also attracted by the sight of large swellings. At the beginning of the season, copulation was not seen or heard until some females had large perineal swellings. At the end, however, copulations occurred with females with small or no swellings. Thus the onset of the mating season is perhaps more determined by the reproductive state of the females than is the end. There was some evidence in support of the idea that an increase in female aggression towards males separates the sexes after the mating season.

During the mating period, it seemed that two social movements were taking place: males were joining female-with-small-juvenile groups, and at the same time females were leaving their small juveniles in such groups and joining groups of adult males. At the beginning of the mating season, males first moved into female groups, females moved out rather later to join males. At the end, in A troop, it seemed that males were withdrawing from the mainly female groups and the remaining receptive females were to be found in mainly male groups. Thus, movements of males between sub-groups characterized both the beginning and the end of the season, though at the end they may have been chiefly responding to aggression from the newly pregnant females.

For the duration of the mating season, there is a fundamental social reorganization of a talapoin troop. Such complex changes in behaviour suggest a strong selection value in highly synchronized breeding for this species. It is possible that there is some specific item of diet available for only a limited period of time which can most profitably be utilized at a particular stage of the reproductive cycle. The apparent wealth and variety of food supply makes this suggestion unattractive at first sight though a careful study might reveal such a limiting factor. It is also possible that it is the synchrony itself which is important rather than the timing. The very large size of newborn talapoins relative to their mothers must make females unusually vulnerable in late pregnancy; for example, in captivity, they become very lethargic. It might be advantageous for the group to contain such slow moving individuals for as brief a time as possible.

\section{ACKNOWLEDGMENTS}

This study was supported by a grant from the Leverhulme Trust to A.F.D. and by the National Geographic Society to T.E.R. The skilled and patient assistance of Joseph Djampene and Jules were also essential to the success of this study, and we are indebted to the Faculty of Science, University of Cameroon, and the École des Eaux et Forêts Mbalmayo for hospitaltity and assistance.

\section{REFERENCES}

Baldwin, J. D. (1970) Reproductive synchronisation in squirrel monkeys (Saimiri). Primates, 11, 317326.

Dixson, A. F., Everitt, B. J., Herbert, J., Rugman, S. M. \& Scruton, D. M. (1973) Hormonal and other determinants of sexual attractiveness and receptivity in rhesus and talapoin monkeys. In Primate Reproductive Behavior, vol. 2, pp. 36-63. Ed. C. H. Phoenix. Karger, Basel.

Dixson, A. F., Scruton, D. M. \& Herbert, J. (1975) Behaviour of the talapoin monkey (Miopithecus talapoin) studied in groups, in the laboratory. F. Zool., Lond. 176 (in press). 
Gautrer-Hron, A. (1966) L'écologie et l'éthologie du talapoin (Miopithecus talapoin). Biol. gabon. 2, 311329.

Gautier-Hion, A. (1968) Etude du cycle annuel de reproduction du talapoin (Miopithecus talapoin) vivant dans son milieu naturel. Biol. gabon. 4, 163-173.

Gautier-Hron, A. (1971a) L'écologie du talapoin du Gabon. Terre et Vie, 25, 427-490.

GAUTIER-Hion, A. (1971b) Repertoire comportemental du talapoin (Miopithecus talapoin). Biol.gabon. 7, 295-391.

Kauman, J. H. (1965) A three year study of mating behaviour in a free-ranging band of rhesus monkeys. Ecology, 46, 500-512.

Rowels, T. E. (1972) Toward a natural history of the talapoin monkey in Cameroon. Annls Fac. Sci. Cameroon, 10, 121-134.

RowedL, T. E. (1973) Social organization of wild talapoin monkeys. Am. 7. phys. Anthrop. 38, 359-397.

Scruton, D. M. \& Herbert, J. (1970) The menstrual cycle and its effect upon behaviour in the talapoin monkey (Miopthecus talapoin). F. Zool., Lond. 162, 419-436.

VAN HORN, R. N. (1975) Primate breeding season: photoperiodic regulation in captive Lemur catta. Folia primat. (in press).

VANDENBERGH, J. G. (1973) Environmental influences on breeding in rhesus monkeys. In Primate Reproductive Behavior, vol. 2, pp. 1-17. Ed. C. H. Phoenix. Karger, Basel.

Wilson, A. P. \& BoelKINs, R. C. (1970) Evidence for seasonal variation in agressive behaviour by Macaca mulatta. Anim. Behav. 18, 719-724.

Wolfheim, J. H. \& Rowell, T. E. (1972) Communication among captive talapoin monkeys (Miopithecus talapoin). Folia primat. 18, 224-255. 